\title{
Nasal Cavity and Ethmoid Sinus Cancer pT0 TNM Finding v6 and v7
}

National Cancer Institute

\section{Source}

National Cancer Institute. Nasal Cavity and Ethmoid Sinus Cancer pTo TNM Finding v6

and v7. NCI Thesaurus. Code C65049.

Nasal cavity and ethmoid sinus cancer with no evidence of a primary tumor. (from AJCC 6th and 7th Eds.) 